\title{
Dissipation and residue of pymetrozine in rice field ecosystem
}

\author{
Yanfeng Zhang $\cdot$ Li Zhang $•$ Peng Xu • Jianzhong Li $•$ Huili Wang
}

Received: 14 February 2014 / Accepted: 29 December 2014 / Published online: 6 February 2015

(C) Springer International Publishing Switzerland 2015

\begin{abstract}
The dissipation and residue of pymetrozine in rice field ecosystem were studied based on a novel and reliable analytical method for pymetrozine in paddy water, soil, rice straw, brown rice, and rice husk. The pymetrozine residues were extracted with acetonitrile and cleaned up by Carb- $\mathrm{NH}_{2}$ SPE cartridge and determined by high-performance liquid chromatography electrospray ionization tandem mass spectrometry (LCESI-MS-MS). The dissipation of pymetrozine followed first-order kinetics and its half-lives ranged from 1.7 to 1.8 days in paddy water, 5.1 to 5.7 days in soil, and 2.3 to 2.6 days in rice straw, respectively. At harvest time, the highest final residues of pymetrozine varied in soil among three geographical fields and were below the limit of detection in rice tissues. The recommended dosage was considered to be safe for human beings and animals, and the results were helpful in setting maximum residue limit for pymetrozine in rice.
\end{abstract}

Keywords Dissipation · Residue · Pymetrozine · Rice field

Pesticides, which in general protect plants from damaging influences such as weeds, diseases, or insects, are important and indispensable to the agricultural

Y. Zhang $\cdot$ L. Zhang $\cdot$ P. Xu $\cdot$ J. Li $\cdot$ H. Wang $(\bowtie)$

Research Center for Eco-Environmental Sciences,

Chinese Academy of Sciences,

Beijing 100085, China

e-mail: huiliwang@rcees.ac.cn production. Although the use of pesticides provides incontrovertible benefits on food and nutrition, the superfluous and injudicious use of pesticides causes widespread contamination of environment and food, which is harmful to the environmental safety and human health (Bhanti and Taneja 2007; Zhang et al. 2010). Hence, it is necessary to evaluate the dissipation and residue of pesticides under the specific climatic conditions in which agricultural practice takes place (Yi and $\mathrm{Lu}$ 2006). Rice, which is rich in carbohydrates, proteins, minerals, and vitamins, is the most widely staple food for the majority of people in the world. As rice production is being affected by Aphids, Delphacidae, Aleyrodidae, and Cicadellidae, many kinds of pesticides were used to protect the rice from pests.

Pymetrozine, 4,5-dihydro-6-methyl-4-[(3pyridylmethylene)-amino]-1,2,4-triazin-3(2H)-one (Fig. 1), is a novel pesticide with effects on neuroregulation or nerve-muscle interaction against sucking insects by preventing these ones from inserting their stylus into the plant tissue (Lashkari et al. 2007; Li et al. 2011; Shen et al. 2009). Pymetrozine has been widely used in rice fields in China for the control of aphids, whiteflies, and plant hoppers as a substitution of highly toxic organophosphate pesticides. Though pymetrozine is registered for use in various crops and vegetables because of the broad-spectrum activity, the EPA has considered that pymetrozine is a "likely" human carcinogen and is slightly to moderately toxic to aquatic invertebrates (Zhang et al. 2007; EPA 2000). Therefore, pymetrozine residues may lead to potential health injury. Several analysis methods have been 
developed for residues of pymetrozine in different matrices, such as differential pulse polarographic method (DPP), liquid chromatography (LC) with UV/vis, diode array detection (DAD), and mass spectrometry (MS); however, the fast and efficient method is LC with mass spectrometry (MS) (Guan et al. 2013; Abd Al-Rahman et al. 2012; Lehotay et al. 2010; Mercan et al. 2007; Lee et al. 2011). A simple, sensitive, and selective method with LC-MS/MS for quantification of pymetrozine was developed to study the dissipation behavior and final residue of pymetrozine in rice field ecosystem.

\section{Materials and methods}

Chemicals and reagents

Pymetrozine standard (98.0 \%) and its formulation (50 \% WG) were provided by Jiangsu Tianrong Group Co., Ltd. (Jiangsu, China); acetonitrile and formic acid for HPLC analysis were chromatographic grade and acetonitrile for sample preparation; dichloromethane, toluene, ammonium hydroxide ( $25 \%$ ), anhydrous sodium sulfate, and sodium chloride were analytical grade; all of them were purchased from Dikma Co., Ltd. (Beijing, China); deionized water was purified with a Milli-Q water purification system (Millipore, USA); Carb- $\mathrm{NH}_{2}(500 / 500 \mathrm{mg})$ SPE cartridge was obtained from Agela Technologies Inc. (Tianjin, China).

Field trials

Field trials were carried out in supervised rice field in Zhejiang, Anhui, and Beijing in two consecutive years, respectively. Each trial plot was $30 \mathrm{~m}^{2}$ and separated with isolation belt.

The dissipation kinetic study was conducted in six plots. A complete randomized block design was applied with three replicates. Pymetrozine formulations were sprayed at $135 \mathrm{~g}$ a.i. $\mathrm{hm}^{-2}$ (1.5 times of the recommended

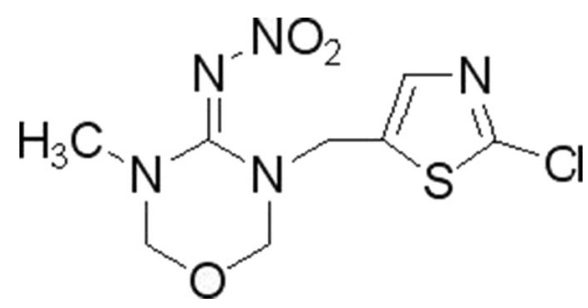

Fig. 1 Chemical structure of pymetrozine dose) once, and three untreated plots were sprayed with water as a control. Representative samples were collected at random on 0 ( $2 \mathrm{~h}$ after spraying), 1, 3, 5, 7, 14, 21, 30, 45 , and 60 days after application of pymetrozine and stored in a deep freezer $\left(-20^{\circ} \mathrm{C}\right)$ before further analysis.

The final residue study was performed with two dosage levels, $90 \mathrm{~g}$ a.i. $\mathrm{hm}^{-2}$ (recommended dose) and $135 \mathrm{~g}$ a.i. $\mathrm{hm}^{-2}$ (1.5 times of the recommended dose). The treated plots were sprayed two and three times with an interval of 15 days between each application. Representative samples, including soil, rice straw, brown rice, and rice husk were collected randomly with an interval of 7 days and stored in a deep freezer $\left(-20^{\circ} \mathrm{C}\right)$ before further analysis.

Sample preparation

A $50 \mathrm{~mL}$ aliquot of paddy water sample, $3 \mathrm{~mL}$ of ammonium hydroxide, and $15 \mathrm{~g}$ of sodium chloride were placed in a $250-\mathrm{mL}$ separatory funnel, and pymetrozine was extracted with $50 \mathrm{~mL}$ of dichloromethane by shaking vigorously for $30 \mathrm{~s}$. The lower organic portion was filtered through anhydrous sodium sulfate, and another $30 \mathrm{~mL}$ of dichloromethane was added successively for extraction once again. The extracts were combined and evaporated to dryness at $40{ }^{\circ} \mathrm{C}$ by the rotary evaporator. The residue was dissolved in $5 \mathrm{~mL}$ of acetonitrile and then filtered through a $0.22-\mu \mathrm{m}$ filter before liquid chromatography electrospray ionization tandem mass spectrometry (LC-ESI-MS/MS) analysis.

The soil sample was prepared by removing any large stones. The rice tissue samples (rice straw, brown rice, and rice husk) were grinded in a grinder for homogenization separately. The same extraction and cleanup method was used for soil, rice straw, brown rice, and rice husk. A $10 \mathrm{~g}$ aliquot of samples and $3 \mathrm{~mL}$ of ammonium hydroxide were placed into a $150-\mathrm{mL}$ Erlenmeyer flask and extracted with $50 \mathrm{~mL}$ acetonitrile/water $(3 / 1, v / v)$ by shaking on a shaker for $1 \mathrm{~h}$, and then the extract was filtrated. After adding $5 \mathrm{~g}$ of sodium chloride, the filtrate was shaken and stratified. The upper layer was evaporated to dryness at $40{ }^{\circ} \mathrm{C}$ by the rotary evaporator.

Cleanup was performed on a Carb- $\mathrm{NH}_{2}$ SPE cartridge $(500 / 500 \mathrm{mg}, 6 \mathrm{~mL})$. The Carb- $\mathrm{NH}_{2}$ cartridge was preconditioned with $10 \mathrm{~mL}$ of acetonitrile/toluene $(3 / 1, v / v)$. The concentrated extracts dissolved with $2 \mathrm{~mL}$ of acetonitrile were transferred to the cartridge and the effluent was discarded. The analyte was eluted with $10 \mathrm{~mL}$ of acetonitrile/toluene $(3 / 1, v / v)$. The 
Table 1 LC-ESI-MS/MS parameters for pymetrozine

\begin{tabular}{lclll}
\hline $\begin{array}{l}\text { Parent } \\
\text { ion }(\mathrm{m} / \mathrm{z})\end{array}$ & $\begin{array}{l}\text { Product } \\
\text { ion }(\mathrm{m} / \mathrm{z})\end{array}$ & Purpose & $\begin{array}{l}\text { Dwell } \\
\text { time }(\mathrm{s})\end{array}$ & $\begin{array}{l}\text { Collision } \\
\text { energy }(\mathrm{eV})\end{array}$ \\
\hline 218 & 78 & qualification & 200 & 40 \\
218 & 105 & quantification & 200 & 20 \\
\hline
\end{tabular}

collected eluent was evaporated to dryness at $40^{\circ} \mathrm{C}$ by a rotary evaporator. The residue was dissolved in $1 \mathrm{~mL}$ of acetonitrile and then filtered through a $0.22-\mu \mathrm{m}$ filter before LC-ESI-MS/MS analysis.

\section{Instrument conditions}

An Agilent 1260-6460 QQQ LC-ESI-MS/MS (Agilent Technology, USA) was used to analyze the pymetrozine. Separation was carried out on Agilent SB-C18 column $(50 \mathrm{~mm} \times 2.1 \mathrm{~mm}$ I.D., $1.8 \mu \mathrm{m})$ at $25{ }^{\circ} \mathrm{C}$. The mobile phase consisted of acetonitrile/ $0.1 \%$ formic acid aqueous solution $(70 / 30, v / v)$ with the flow rate of $0.20 \mathrm{~mL} / \mathrm{min}$. The injection volume was $10 \mu \mathrm{L}$, and the run time was $3.0 \mathrm{~min}$. Detection was carried out on tandem quadrupole mass spectrometry with the electrospray ionization (ESI) positive ion mode. The optimized parameters were as follows: capillary voltage, $4000 \mathrm{~V}$; drying gas temperature, $350^{\circ} \mathrm{C}$; drying gas flow, $10 \mathrm{~mL} / \mathrm{min}$; nebulizer pressure, $15 \mathrm{psi}$; and fragmentor voltage, $110 \mathrm{~V}$. Acquisition was conducted in multiple reaction monitoring mode with the parameters shown in Table 1 . The retention time of pymetrozine was about $0.8 \mathrm{~min}$.

\section{Statistical analysis}

The dissipation kinetics of pymetrozine in paddy water, soil, and rice straw were indicated by the first-order kinetics equations $\left(C_{t}=C_{0}^{-k t}\right)$ and the half-life $\left(t_{1 / 2}=\right.$ $\ln 2 / k$ ), where $C_{t}$ denotes the concentration of the pesticide residue at the time of $t, C_{0}$ denotes the initial deposits after application, and $k$ is the degradation rate constant.

\section{Results and discussion}

\section{Validation}

Samples were quantified using external standards, and the linear calibration curve was obtained in the range of

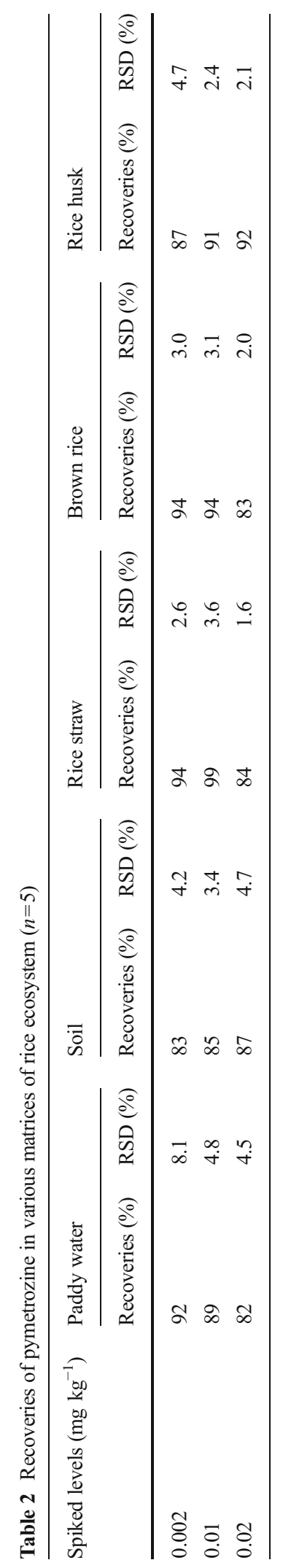


$0.002-2.0 \mathrm{mg} \mathrm{L}^{-1}$ with six calibration points $(0.002$, $0.02,0.2,0.5,1.0$, and $2.0 \mathrm{mg} \mathrm{L}^{-1}, y=530079 x-3503$, $\left.R^{2}=0.9994\right)$. The average recoveries of pymetrozine in matrices that were studied at three fortification levels were $82-99 \%$, and the RSDs of the recovery data were 1.6-8.1\% (Table 2). All recoveries and RSDs were within the permissible range. The representative chromatograms for various matrices spiked with pymetrozine were shown in Fig. 2. The limit of detection (LOD) in sample was $6.0 \times 10^{-12} \mathrm{~g}$ at a signal-tonoise $(\mathrm{S} / \mathrm{N})$ ratio of $3: 1$. The limit of quantification (LOQ) was $0.002 \mathrm{mg} \mathrm{kg}^{-1}$ in sample based on $\mathrm{S} / \mathrm{N}$ ratio with 10:1.

\section{Dissipation of pymetrozine in rice field ecosystem}

The dissipation of pymetrozine in rice field ecosystem followed the first-order kinetics, and the persistence of pymetrozine in environment was characterized by the half-life. Statistical parameters and the half-life of pymetrozine residue dissipation were summarized in Table 3.

The initial deposit of pymetrozine in paddy water was $0.031,0.029$, and $0.033 \mathrm{mg} \mathrm{kg}^{-1}$ in Anhui, Beijing, and Zhejiang, respectively, and then declined
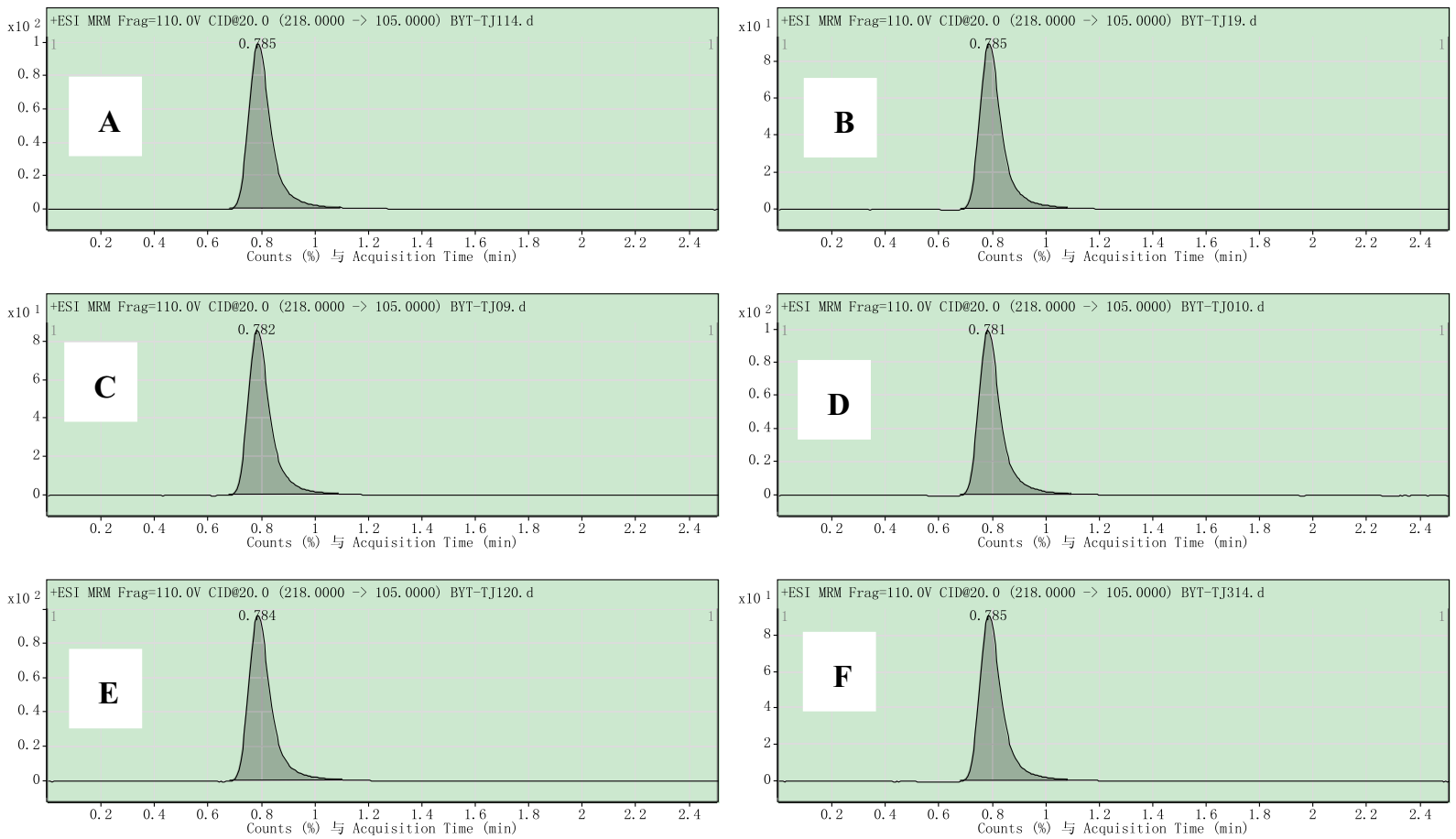

Fig. 2 LC-MS/MS chromatograms in MRM acquisition mode of pymetrozine spiked in matrices $\left(0.01 \mathrm{mg} \mathrm{kg}^{-1}\right)$ : a standard b water; $\mathbf{c}$ soil; d rice straw; e brown rice; and $\mathbf{f}$ rice husk 
Table 3 Regression equation and half-life of pymetrozine in water, soil, and rice straw

\begin{tabular}{|c|c|c|c|c|c|c|c|c|c|}
\hline \multirow[t]{2}{*}{ Samples } & \multicolumn{3}{|l|}{ Anhui } & \multicolumn{3}{|l|}{ Beijing } & \multicolumn{3}{|l|}{ Zhejiang } \\
\hline & Equation & $R^{2}$ & $t_{1 / 2}$ (days) & Equation & $R^{2}$ & $t_{1 / 2}$ (days) & Equation & $R^{2}$ & $t_{1 / 2}$ (days) \\
\hline Water & $y=0.0327 \mathrm{e}^{-0.403 x}$ & 0.9886 & 1.7 & $y=0.0278 \mathrm{e}^{-0.379 x}$ & 0.9856 & 1.8 & $y=0.0374 \mathrm{e}^{-0.387 x}$ & 0.9669 & 1.8 \\
\hline Soil & $y=0.0872 \mathrm{e}^{-0.130 x}$ & 0.7013 & 5.3 & $y=0.0813 \mathrm{e}^{-0.122 x}$ & 0.7939 & 5.7 & $y=0.154 \mathrm{e}^{-0.137 x}$ & 0.8256 & 5.1 \\
\hline Rice straw & $y=0.0679 \mathrm{e}^{-0.295 x}$ & 0.8127 & 2.3 & $y=0.0747 \mathrm{e}^{-0.265 x}$ & 0.8183 & 2.6 & $y=0.0807 \mathrm{e}^{-0.305 x}$ & 0.8320 & 2.3 \\
\hline
\end{tabular}

residue was below limit of detection after 21 days. The results showed that a sharp decline of residue level in the first 2 weeks, which was similar to that 79.02 and $87.28 \%$ of the initial residue levels had already dissipated after 10 days of application at the recommended dose and double dose, respectively (Hong et al. 2011).

Terminal residues of pymetrozine in rice straw, brown rice, rice husk, and soil

The soil and rice tissues were sampled during the harvest period and the final residues of pymetrozine in soil were listed in Table 4. When pymetrozine was applied at the recommended dosage over two or three times, the final residue of pymetrozine in soil were $0.023-0.381$, 0.004-0.099, and <LOQ-0.040 $\mathrm{mg} \mathrm{kg}^{-1}$ after 7, 14, 21 days, respectively; the pymetrozine residue was below the limit of detection in rice tissues. When pymetrozine was applied at the double recommended dosage over two or three times, the final residue of pymetrozine in soil were $0.052-2.857,0.010-0.373$, and $0.012-0.099 \mathrm{mg} \mathrm{kg}^{-1}$ after $7,14,21$ days, respectively; the pymetrozine residue was below the limit of detection in rice tissues. Pymetrozine was safety in rice field ecosystem at harvest time, and 7 days interval between application and harvest was thought to be safe. The trace residue of pymetrozine in soils may be attributed to the assistance of organic carbon content in the soils, increasing soil moisture or solubility in water.

Safety evaluation

The overall results obtained in this survey reveal some interesting patterns for the levels and the origin of pymetrozine quantified in paddy water, soil, and rice tissues and assist in valuable future scientific assessment on pymetrozine residual contamination in the regions. On the other hand, considering the discrimination of natural and anthropogenic sources of the investigated pymetrozine in rice field ecosystem, pymetrozine which was a water-soluble and polar pesticide, could access to the water easily and pollute it readily. Finally, degradation products or metabolites produced by hydrolysis, photolysis, or biotic-mediated processes, which could
Table 4 Final residues of pymetrozine in soil

\begin{tabular}{|c|c|c|c|c|c|c|}
\hline \multirow{2}{*}{$\begin{array}{l}\text { Table } 4 \text { Final residues of } \\
\text { pymetrozine in soil }\end{array}$} & \multirow[t]{2}{*}{ Dosage (g a.i. $\mathrm{hm}^{-2}$ ) } & \multirow[t]{2}{*}{ Spraying times } & \multirow[t]{2}{*}{ Sampling time (days) } & \multicolumn{3}{|c|}{ Final residue $\left(\mathrm{mg} \mathrm{kg}^{-1}\right)$} \\
\hline & & & & Anhui & Beijing & Zhejiang \\
\hline & \multirow[t]{6}{*}{90} & \multirow[t]{3}{*}{2} & 7 & 0.023 & 0.381 & 0.073 \\
\hline & & & 14 & 0.004 & 0.099 & 0.051 \\
\hline & & & 21 & 0.004 & 0.013 & BLD \\
\hline & & \multirow[t]{3}{*}{3} & 7 & 0.029 & 0.302 & 0.116 \\
\hline & & & 14 & 0.010 & 0.081 & 0.057 \\
\hline & & & 21 & $<\mathrm{LOQ}$ & 0.028 & 0.040 \\
\hline & \multirow[t]{5}{*}{135} & \multirow[t]{3}{*}{2} & 7 & 0.052 & 0.708 & 0.125 \\
\hline & & & 14 & 0.010 & 0.084 & 0.114 \\
\hline & & & 21 & 0.012 & 0.080 & 0.035 \\
\hline & & \multirow[t]{3}{*}{3} & 7 & 1.032 & 2.857 & 0.170 \\
\hline & & & 14 & 0.181 & 0.373 & 0.120 \\
\hline$<L O Q$ below the limit of & & & 21 & 0.099 & 0.040 & 0.024 \\
\hline
\end{tabular}

$<L O Q$ below the limit of quantification 
have the potential to contaminate the rice field ecosystem and produce human health risk, should be taken into consideration in the future investigation.

\section{Conclusions}

A residue analytical method has been developed and validated for determination of pymetrozine in rice field ecosystem. The results showed that the half-life of pymetrozine in rice field ecosystem was less than 5.7 days. The degradation rates of pymetrozine were in the following order: paddy water $>$ rice straw $>$ soil. The final residues of pymetrozine in rice tissues (rice straw, brown rice, and rice husk) were below the MRLs (0.02 $\mathrm{mg} \mathrm{kg}^{-1}$, fixed by EU) after 7 days, so it was safe for human beings and the environment and the safe interval was 7 days. This proposed analytical procedure was fast, easy to perform, and could be utilized for regular monitoring of pymetrozine residues in rice field. This work would contribute to provide guidance on safe and proper use of the pesticide.

Acknowledgments This work was supported by grants from the Institute for the Control of Agrochemicals, Ministry of Agriculture of the People's Republic of China.

\section{References}

Abd Al-Rahman, S. H., Almaz, M. M., \& Ahmed, N. S. (2012). Dissipation of fungicides, insecticides, and acaricide in tomato using HPLC-DAD and QuEChERS Methodology. Food Analytical Methods, 5, 564-570.

Bhanti, M., \& Taneja, A. (2007). Contamination of vegetables of different seasons with organophosphorous pesticides and related health risk assessment in northern India. Chemosphere, 69, 63-68.

EPA (2000). United States Environmental Protection Agency. http://www.epa.gov/pesticides/chem_search/reg_actions/
registration/fs_PC-101103 01-Aug-00.pdf Issued August 2000.

Guan, W. B., Li, Z. N., Zhang, H. Y., Hong, H. J., Rebeyev, N., Ye, Y., \& Ma, Y. Q. (2013). Amine modified graphene as reversed-dispersive solid phase extraction materials combined with liquid chromatography-tandem mass spectrometry for pesticide multi-residue analysis in oil crops. Journal of Chromatography A, 1286, 1-8.

Hong, J. H., Lee, C. R., Lim, J. S., \& Lee, K. S. (2011). Comparison of analytical methods and residue patterns of pymetrozine in Aster scaber. Bulletin of Environmental Contamination and Toxicology, 87, 649-652.

Lashkari, M. R., Sahragard, A., \& Ghadamyari, M. (2007). Sublethal effects of imidacloprid and pymetrozine on growth parameters of cabbage aphid, Brevicoryne brassicae on rapeseed, Brassica napus L. Insect Sci., 14, 207-212.

Lee, S. W., Choi, J. H., Cho, S. K., et al. (2011). Development of a new QuEChERS method based on dry ice for the determination of 168 pesticides in paprika using tandem mass spectrometry. Journal of Chromatography A, 1218, 4366-4377.

Lehotay, S. J., Son, K. A., Kwon, H., Koesukwiwat, U., Fu, W. S., Mastovska, K., et al. (2010). Comparison of QuEChERS sample preparation methods for the analysis of pesticide residues in fruits and vegetables. Journal of Chromatography A, 1217, 2548-2560.

Li, C., Yang, T., Huangfu, W. G., \& Wang, Y. L. (2011). Residue and dynamics of pymetrozine in rice field ecosystem. Chemosphere, 82, 901-904.

Mercan, H., Yilmaz, E., \& Inam, R. (2007). Determination of insecticide pymetrozine by differential pulse polarography/ application to lake water and orange juice. Journal of Hazardous Materials, 141, 700-706.

Shen, G. Q., Hu, X., \& Hu, Y. (2009). Kinetic study of the degradation of the insecticide pymetrozine in a vegetablefield ecosystem. Journal of Hazardous Materials, 164, 497501.

Yi, X., \& Lu, Y. T. (2006). Residues and dynamics of probenazole in rice field ecosystem. Chemosphere, 65, 639-643.

Zhang, X., Cheng, X., Wang, C., Xi, Z., \& Li, Q. (2007). Efficient high-performance liquid chromatography with liquid-liquid partition cleanup method for the determination of pymetrozine in tobacco. Annali di Chimica, 97, 295-301.

Zhang, C. Z., Zhang, Z. Y., Liu, X. J., Jiang, W., \& Wu, Y. D. (2010). Dissipation and environmental fate of herbicide H-9201 in carrot plantings under field conditions. Food Chemistry, 119, 874-879. 